\title{
Meningkatkan Kemampuan Meringkas pada Mata Pelajaran Bahasa Indonesia dengan Latihan Bervariasi di Kelas IV SD Negeri 196/IV Alam Barajo Kota Jambi
}

\author{
Eni Abdah ${ }^{1}$
}

\begin{abstract}
Abstrak: Penelitian ini bertujuan untuk meningkatkan kemampuan siswa dalam meringkas dengan penggunaan latihan bervariasi dalam meningkatkan kemampuan siswa dalam meringkas mata pelajaran bahasa Indonesia siswa kelas IV Sekolah Dasar Negeri 196/IV Alam Barajo Kota Jambi, adapun yang dijadikan penilaian kemampuan membaca antara lain :(1) Mampu membaca dengan baik bacaan yang akan diringkas (2) mampu memahami isi secara utuh terhadap bacaan yang akan diringkas (3) mamapu menemukan ide-ide pokok ataupun kalimat topic dalam bacaan yang akan dirangkum dan(4) mampu menyusun kembali ide-ide maupun kalimat topik yang telah ditemukan menjadi sebuah tulisan utuh. Hasil penelitian pada setiap siklus tentang kemampuan siswa dalam meringkas. Pada siklus I kemampuan siswa dalam meringkas nilai rata-rata 52, pada tindakan siklus II mencapai rata-rata 62,19. Pada pelaksanaan siklusIII hasil belajar kemampuan siswa dalam meringkas dengan nilai rata-rata 77,24. Dengan memperhatikan hasil penelitian yang dilaksanakan ,kemampuan yang diperoleh siswa diatas terjadi peningkatan pada setiap siklus yang dilaksanakan untuk itu diharapkan guru bahasa Indonesia kelas IV sekolah dasar dapat menggunakan latihan bervariasi dapat meningkatkan kemampuan siswa dalam meringkas dengan menggunakan latihan bervariasi, sehingga siswa dapat meringkas dengan baik.
\end{abstract}

Kata Kunci : Kemampuan meringkas, metode latihan bervariasi

\begin{abstract}
This study aims to improve students 'ability to summarize with the use of varied exercises in improving students' ability to summarize Indonesian language subjects in grade IV 196 / IV State Elementary School in Alam Barajo, Jambi City. As for the assessment of reading ability include: (1) Able to read the readings to be summarized properly (2) able to comprehend the contents in full to the summaries to be read (3) to be able to find main ideas or sentence topics in the reading that will be summarized and (4) able to rearrange ideas or topic sentences that have been found to be a complete writing. The results of the research in each cycle about students' ability to summarize. In the first cycle the ability of students to summarize the average value of 52, the action of the second cycle reached an average of 62.19. At the cycle III the learning outcomes of students' ability to summarize with an average value of 77.24. By paying attention to the results of the research carried out, the abilities obtained by the students above increase in each cycle carried out for it. It is expected that Indonesian grade 4 elementary school teachers can use varied exercises can improve students' ability to summarize using varied exercises, so students can summarize well.

Keywords: Ability to summarize, varied training methods
\end{abstract}

\section{PENDAHULUAN}

Pembelajaran bahasa Indonesia diarahkan untuk meningkatkan kemampuan peserta didik untuk berkomunikasi dalam bahasa Indonesia dengan baik dan benar, baik secara lisan maupun tulisan,serta menumbuhkan apresiasi terhadap hasil karya kesastraan manusia Indonesia. Standar kompetensi pembelajaran bahasa Indonesia merupakan kualitas kemampuan minimal peserta didik yang menggambarkan penguasaan pengetahuan, keterampilan berbahasa dan sikap positif terhadap bahasa dan sastra indonesia. Standar kompetensi ini merupakan dasar bagi peserta didik untuk memahami dan merespon situasi lokal, regional, nasional dan global. Dalam pembelajaran bahasa Indonesia di kelas IV ada beberapa keterampilan dan kemampuan yang harus dikuasai oleh siswa diantaranya (1) Mendengarkan, (2) Berbicara, (3) Membaca, (4) Menulis. Anonim (1996) mengatakan "mata pelajaran bahasa Indonesia lebih ditekankan untuk mengembangkan kemampuan dan ketrampilan dasar penguasaan bahasa yang meliputi: Mendengarkan, berbicara/bercerita, membaca dan menulis dan mengarang“‘. Dengan demikian pembelajaran bahasa Indonesia memungkinkan siswanya untuk saling berhubungan dan berkomunikasi.

\footnotetext{
${ }^{1}$ Sekolah Dasar Negeri 196/IV Alam Barajo Kota Jambi
} 
Pada pembelajaran bahasa Indonesia di kelas IV, seharusnya siswa mampu menanggapi penjelasan yang disampaikan, membaca cepat, memerankan drama, menulis karangan, dan mampu mengungkapkan kalimat secara lisan. Namun pada kenyataannya, pada pembelajaran bahasa Indonesia banyak siswa tidak bisa mencapai indikator yang telah ditentukan, diantaranya kemampuan menulis ringkasan. Menulis merupakan salah satu dari empat aspek keterampilan berbahasa. Keterampilan menulis mempunyai peranan sangat penting bagi siswa pada jenjang pendidikan karena keterampilan menulis merupakan langkah awal untuk memperoleh pengetahuan dari berbagai macam disiplin ilmu yang dipelajari. Metologi pembelajaran yang seharusnya dipakai oleh guru mengikuti tahapan,kegiatan awal, kegiatan inti dan kegiatan akhir yang tersusun dalamRencana Pelaksanaan Pembelajaran (RPP). Pada pelaksanaan sehari-hari guru kelas harus banyak menguasai bidang studi membuat cara mengajar guru menjadi terlalu formal antara guru dengan siswa hampir tidak ada komunikasi dengan baik. Proses yang dilakukan guru setalah menjelaskan pelajaran, siswa tidak diberi kesempatan untuk bertanya, guru langsung memberi latihan. Sedangkan 62,5\% yang lainnya kebanyakan diam dan mendengar tidak berani mengungkapkan apa yang ada dalam isi hatinya. Guru tidak memberi contoh yang mengarah kepada tujuan pembelajaran, tidak menggunakan metode dan media yang sesuai yang menarik minat siswa untuk mengikuti proses pembelajaran.Diantaranya kegiatan menulis ringkasan pada mata pelajaran Bahasa Indonesia.

Berdasarkan observasi, diketahui faktor penyebab rendahnya kemampuan siswa dalam menulis ringkasan, ada beberapa penyebab dari masalah ini yaitu faktor dari siswa itu sendiri dan faktor dari guru yang merangkap sebagai gurubidang studi. Faktor penyebab dari siswa adalah siswa kurang mampu menulis kalimat bahasa Indonesia dengan baik dan benar, masih banyak siswa yang belum mampu menulis ringkasan yang sesuai sebagaimana yang dikadarkan didalam kurikulum KTSP 2006. Adapun faktor guru selama ini guru menggangap siswahanya sebagai objek pembelajaran yang membuat siswa bersifat pasif, guru lebih banyak berbicara dan tidak memberikan kesempatan kepada siswa seluas-luasnya menjelaskan, menggungkapkan, bertanya dan memberi pertanyaan, sehingga apa yang ada di benak dan hati siswa tidak bisa tersalurkan. Adapun faktor lain yaitu faktor lingkungan yang keseharian siswa tidak menggunakan bahasa Indonesia. Hasilnya menunjukkan dari 24 orang siswa hanya 3 orang $(12,5 \%)$ yang mapan menulis ringkasan yang baik dan benar, melihat kondisi tersebut peneliti terpanggil untuk dapat mengatasinya dengan metode latihan bervariasi. Hal itu yang melatarbelakangi peneliti bekerja sama dengan guru kelas untuk mengadakan penelitian tindakan kelas ini dengan harapan dapat meningkatkan kemampuan siswa kelas IV SD Negeri 196/IV Alam Barajo dengan melakukan beberapa tindakan pembelajaran menulis ringkasan yang baik dan benar sesuai dengan kaidah bahasa Indonesia.

\section{METODE PENELITIAN}

Subjek dalam penelitian ini adalah siswa kelas IV SDN 196/IV Alam Barajo dengan jumlah siswa 24 orang,siswa laki-laki terdiri dari 13 orang dan siswa perempuan 11 orang. Penelitian ini dilaksanakan pada tahun ajaran 2017/2018 pada semester II yang dilaksanakan selama 3 bulan mulai dari bulan Januari sampai Maret yang terdiri dari 3 siklus yang setiap siklus diadakan 2 kali pertemuan. Prosedur penelitian merupakan tahap yang dilakukan pada pelaksanaanpenelitian antara lain: Perencanaan, pelaksanaan, observasi dan refleksi.Perencanaan sebelum melaksanakan tindakan,peneliti merencanakan hal-hal sebagai berikut: (1) Mengadakan penjajakan untuk mendapatkan masalah pembelajaran Bahasa Indonesia dengan cara mengamati dan member tugas menulis paragrap. (2) Menyiapkan instrumen berupa catatan pengamatan (terlampir).(3) Menyiapkan bahan pelajaran berupa RPP dan media pembelajaran lain yang mendukung, adapun rencana awal berupa konsep adalah sebagai tujuan meningkatkan kemampuan siswa dalam menulis ringkasan. Pengamatan dilakukan didalam penilaian ini untuk memperoleh data kuantitatif. Untuk menjaring data ini menggunakan instrumen penilaian dengan mengamati kemampuan siswa menulis ringkasan.Untuk mendapatkan data mengenai aktivitas siswa pada saat belajar mengajar berlangsung menggunakan instrumen pengamatan berikut. (a) Kesiapan siswa untuk belajar, (b) Aktifitas siswa dalam belajar.Data kuantitatif ini menjadi masukan bagi peneliti untuk menyempurnakan tindakan pada siklus berikutnya. Kemudian data ini juga akan dibahas pada hasil penelitian sehingga dapat melengkapi data kemampuan menulis ringkasan yang diperoleh siswa. 


\section{HASIL DAN PEMBAHASAN}

\section{Siklus I}

Tabel 1.

Hasil Observasi Proses Belajar Tindakan Siklus I Penerapan Latihan Bervariasi Pada Menulis Ringkasan Pembelajaran Bahasa Indonesia Siswa Kelas IV SD Negeri 196/IV

Alam Barajo Tahun 2018

\begin{tabular}{|c|c|c|c|c|c|c|c|}
\hline \multirow{2}{*}{ No } & \multirow[b]{2}{*}{ Nama } & \multicolumn{3}{|c|}{ Aspek yang diobservasi } & \multirow[b]{2}{*}{ Jlh } & \multirow[b]{2}{*}{ Rata-Rata } & \multirow{2}{*}{ Predikat } \\
\hline & & 1 & 2 & 3 & & & \\
\hline 1 & Alif Rafizd & 3 & 3 & 4 & 10 & 3,33 & $\mathrm{CB}$ \\
\hline 2 & Angelina Maharani & 3 & 3 & 4 & 10 & 3,33 & $\mathrm{CB}$ \\
\hline 3 & Arif Tarmisih & 2 & 4 & 4 & 10 & 3,33 & $\mathrm{CB}$ \\
\hline 4 & Amelia & 2 & 3 & 3 & 8 & 2,67 & $\mathrm{~K}$ \\
\hline 5 & Bima Arta Kusuma & 2 & 3 & 3 & 9 & 3 & $\mathrm{CB}$ \\
\hline 6 & Fadli & 2 & 3 & 2 & 7 & 2,33 & $\mathrm{~K}$ \\
\hline 7 & Indah Permata Sari & 2 & 3 & 4 & 9 & 3 & $\mathrm{CB}$ \\
\hline 8 & Jazirah El Fitriyanti & 2 & 3 & 2 & 11 & 3,67 & $\mathrm{CB}$ \\
\hline 9 & Julian Pasha & 2 & 3 & 4 & 9 & 3 & $\mathrm{CB}$ \\
\hline 10 & Luvia Pranesti & 2 & 3 & 3 & 8 & 2,67 & $\mathrm{~K}$ \\
\hline 11 & Lily Angelica & 2 & 3 & 3 & 8 & 2,67 & $\mathrm{~K}$ \\
\hline 12 & M. Alfio & 3 & 3 & 3 & 9 & 3 & $\mathrm{CB}$ \\
\hline 13 & M. Rafi & 2 & 3 & 4 & 9 & 3 & $\mathrm{CB}$ \\
\hline 14 & Meisya Dwi Lestari & 3 & 3 & 3 & 9 & 3 & $\mathrm{CB}$ \\
\hline 15 & M. Adli & 2 & 3 & 3 & 8 & 2,67 & $\mathrm{~K}$ \\
\hline 16 & Musa Riski Haposan & 2 & 3 & 4 & 9 & 3 & $\mathrm{CB}$ \\
\hline 17 & R. Aisyah Azzahra & 2 & 3 & 3 & 8 & 2,67 & $\mathrm{CB}$ \\
\hline 18 & Riska Aura & 3 & 3 & 3 & 9 & 3 & $\mathrm{CB}$ \\
\hline 19 & Riski Armando & 3 & 4 & 3 & 10 & 3,33 & $\mathrm{CB}$ \\
\hline 20 & Laili Homisanti & 2 & 4 & 3 & 9 & 3 & $\mathrm{CB}$ \\
\hline 21 & Nurhasanah & 2 & 3 & 3 & 8 & 2,67 & $\mathrm{~K}$ \\
\hline 22 & Clara Claudia Ardhika & 3 & 4 & 4 & 11 & 3,67 & $\mathrm{CB}$ \\
\hline 23 & Eka Syarifuddin & 2 & 3 & 3 & 8 & 2,67 & $\mathrm{~K}$ \\
\hline 24 & Fikriansyah & 3 & 4 & 3 & 10 & 3,33 & $\mathrm{CB}$ \\
\hline \multicolumn{2}{|c|}{ Jumlah Nilai } & 58 & 78 & 80 & 216 & 72,01 & \\
\hline \multicolumn{2}{|c|}{ Rata-Rata } & 2,41 & 3,25 & 3,33 & 9 & & $\mathrm{CB}$ \\
\hline
\end{tabular}

Tabel 2.

Rentang Nilai Hasil Observasi Siklus I Siswa Kelas IV SD Negeri 196/IV Alam Barajo Tahun 2018

\begin{tabular}{|l|l|l|l|}
\hline Nilai Angka & Predikat & Jumlah Siswa & Persentase \% \\
\hline 5 & Sangat Baik & - & - \\
\hline 4 & Baik & - & - \\
\hline 3 & Cukup Baik & 17 siswa & $70,83 \%$ \\
\hline 2 & Kurang & 7 siswa & $29,17 \%$ \\
\hline 1 & Sangat Kurang & - & - \\
\hline JUMLAH & & 24 siswa & $100 \%$ \\
\hline
\end{tabular}

Tabel 3.

Nilai Hasil Belajar Siswa pada Siklus I dalam Meringkas dengan Menggunkan Latihan Bervariasi Siswa Kelas IV SD Negeri 196/IV Alam Barajo Tahun 2018

\begin{tabular}{|c|c|c|c|c|c|c|c|c|}
\hline \multirow{2}{*}{ No } & \multirow{2}{*}{ Nama } & \multicolumn{4}{|c|}{ Aspek yang diobservasi } & \multirow{2}{*}{ Jlh } & \multirow{2}{*}{ Rata-Rata } & \multirow{2}{*}{$\begin{array}{c}\text { Tingkat } \\
\text { Keberhasilan } \\
\end{array}$} \\
\hline & & 1 & 2 & 3 & 4 & & & \\
\hline 1 & Alif Rafizd & 60 & 50 & 40 & 50 & 200 & 50 & KT \\
\hline 2 & Angelina Maharani & & & & & & & KT \\
\hline 3 & Arif Tarmisih & & & & & & & KT \\
\hline 4 & Amelia & & & & & & & KT \\
\hline 5 & Bima Arta Kusuma & & & & & & & KT \\
\hline 6 & Fadli & & & & & & & KT \\
\hline
\end{tabular}




\begin{tabular}{|c|c|c|c|c|c|c|c|}
\hline 7 & Indah Permata Sari & & & & & & $\mathrm{K}$ \\
\hline 8 & Jazirah El Fitriyanti & & & & & & $\mathrm{K}^{7}$ \\
\hline 9 & Julian Pasha & & & & & & $\mathrm{K}$ \\
\hline 10 & Luvia Pranesti & & & & & & $\mathrm{K}^{7}$ \\
\hline 11 & Lily Angelica & & & & & & $\mathrm{K}^{7}$ \\
\hline 12 & M. Alfio & & & & & & $\mathrm{K}$ \\
\hline 13 & M. Rafi & & & & & & $\mathrm{K}$ \\
\hline 14 & Meisya Dwi Lestari & & & & & & $\mathrm{K}$ \\
\hline 15 & M. Adli & & & & & & $\mathrm{K}^{7}$ \\
\hline 16 & Musa Riski Haposan & & & & & & $\mathrm{K}^{\mathrm{T}}$ \\
\hline 17 & R. Aisyah Azzahra & & & & & & $\mathrm{K}$ \\
\hline 18 & Riska Aura & & & & & & $\mathrm{K}^{\top}$ \\
\hline 19 & Riski Armando & & & & & & $\mathrm{K}$ \\
\hline 20 & Laili Homisanti & & & & & & $\mathrm{K}^{7}$ \\
\hline 21 & Nurhasanah & & & & & & $\mathrm{K}$ \\
\hline 22 & Clara Claudia Ardhika & & & & & & $\mathrm{K}$ \\
\hline 23 & Eka Syarifuddin & & & & & & $\mathrm{K}$ \\
\hline 24 & Fikriansyah & & & & & & $\mathrm{K}^{7}$ \\
\hline \multicolumn{2}{|c|}{$\begin{array}{l}\text { Jumlah Nilai } \\
\text { Rata-Rata }\end{array}$} & 1475 & 1250 & 1090 & 1165 & 4980 & 1248 \\
\hline
\end{tabular}

Keterangan :

1. Mampu membaca dengan baik bacaan yang akan dirangkum

2. Mampu memahami isi secara utuh terhadap bacaan yang akan dirangkum

3. Mampu menemukan ide-ide pokok ataupun kalimat topik dalam bacaan yang akan dirangkum

4. Mampu menyusun kembali ide-ide maupun kalimat topic yang telah ditemukan menjadi sebuah tulisan utuh

Tabel 4.

Rentang Nilai Hasil Belajar Siklus I PTK Penerapan Latihan Bervariasi dalam Kegiatan Meringkas pada Pembelajaran Bahasa Indonesia Siswa Kelas IV SD Negeri 196/IV Alam Barajo Tahun 2018

\begin{tabular}{|l|l|l|l|}
\hline Nilai Angka & Predikat & Jumlah Siswa & Persentase $\%$ \\
\hline $85-10$ & Sangat Tuntas & - & - \\
\hline $75-84$ & Tuntas & - & - \\
\hline $60-74$ & Cukup Tuntas & - & - \\
\hline $40-59$ & Kurang Tuntas & - & $100 \%$ \\
\hline $0-39$ & Sangat Kurang Tuntas & - & - \\
\hline JUMLAH & & 24 siswa & $100 \%$ \\
\hline
\end{tabular}

Jika table diatas dianalisis, nampak bahwa penerapan latihan bervariasi belum dapat meningkatkan kemampuan meringkas dari tingkat ketuntasan yang direncanakan hala ini dapat dilihat dari hasil observasi dan evaluasi pada siklus I. Hasil observasi pada siklus I nilai rata-rata 3,00\% atau predikat cukup baik sedangkan nilai rata-rata hasil evaluasi siklus I adalah 52\% atau predikat kurang tuntas dari jumlah indikator yang diperoleh siswa.

Dari hasil dikemukakan bahwa hasil penelitian pada siklus I diperoleh kesimpulan sebagai berikut proses pembelajaran dengan menggunakan latihan bervariasi belum sepenuhnya dapat meningkatkan kemampuan meringkas siswa indicator yang dapat disimak seperti berikut; a. Proses pembelajaran diukur melalui lembar observasi baru mencapai $70,83 \%$ atau siswa 17 siswa yang mendapat predikat cukup baik sedangkan nilai baik belum ada. b. Dampak lanjutannya adalah nilai rata-rata hasil belajar siswa baru mencapai 52 yang berarti bahwa tingkat penguasaan siswa baru mencapai $52 \%$ dari jumlah indikator kemampuan meringkas dengan kata lain apabila dihubungkan dengan kriteria keberhasilan belum memenuhi kriteria yang ditetapkan yaitu 75Pada identifikasi masalah pada tindakan siklus I ditemukan masalahmasalah sebagai berikut (1) siswa belum terbiasa diarahkan meringkas dengan sebenarnya(2) kurangnya kecepatan mata siswa dalam mengamati kalimat (3) siswa sulit memahami isi pokok suatu bacaan 
Faktor yang dapat menjadi timbulnya masalah tersebut adalah sebagai berikut (1) proses pembelajaran belum begitu terarah (2) siswa belum bisa meringkas dengan sempurna (3) proses pembelajaran belum terlaksana dengan baik. Hasil refleksi berupa rumusan siklus I yang akan diimplementasikan pada siklus II adalah: 1. Siswa perlu diberi tugas stimulus agar mereka tertarik mengikuti sajian pembelajaran disamping itu perlu diingatkan kembali agar siswa mempersiapkan diri lebih baik sebelum mengikuti proses pembelajaran. 2.Tujuan dan manfaat pembelajaran perlu disajikan secara lugas. 3.Memberikan teks bacaan yang lebih menarik. 4.Pada pelaksanaan siklus II perlu diulang kembali tentang teknik meringkas.

\section{Siklus II}

Tabel 5.

Hasil Observasi Proses Belajar Tindakan Siklus II Penerapan Latihan Bervariasi pada Menulis Ringkasan Pembelajaran Bahasa Indonesia Siswa Kelas IV SD Negeri 196/IV Alam Barajo Tahun 2018

\begin{tabular}{|c|l|c|c|c|c|c|c|}
\hline \multirow{2}{*}{ No } & \multirow{2}{*}{ Nama Siswa } & \multicolumn{3}{|c|}{$\begin{array}{c}\text { Aspek yang } \\
\text { diobservasi }\end{array}$} & \multirow{2}{*}{ Jlh } & \multirow{2}{*}{$\begin{array}{c}\text { Rata } \\
\text { Rata }\end{array}$} & \multirow{2}{*}{ Predikat } \\
\cline { 3 - 5 } & & 1 & 2 & 3 & & & \\
\hline 1 & Alif Rafizd & 4 & 4 & 4 & 12 & 4 & B \\
\hline 2 & Angelina Maharani & 4 & 4 & 4 & 12 & 4 & B \\
\hline 3 & Arif Tarmisih & 3 & 4 & 4 & 11 & 3,67 & CB \\
\hline 4 & Amelia & 3 & 4 & 4 & 11 & 3,67 & CB \\
\hline 5 & Bima Arta Kusuma & 3 & 4 & 4 & 11 & 3,67 & CB \\
\hline 6 & Fadli & 3 & 4 & 3 & 10 & 3,67 & CB \\
\hline 7 & Indah Permata Sari & 3 & 4 & 4 & 11 & 3,67 & CB \\
\hline 8 & Jazirah El Fitriyanti & 4 & 4 & 4 & 12 & 4 & B \\
\hline 9 & Julian Pasha & 4 & 4 & 4 & 12 & 4 & \\
\hline 10 & Luvia Pranesti & 3 & 4 & 4 & 11 & 3,67 & CB \\
\hline 11 & Lily Angelica & 3 & 4 & 4 & 11 & 3,67 & CB \\
\hline 12 & M. Alfio & 4 & 4 & 4 & 12 & 4 & B \\
\hline 13 & M. Rafi & 3 & 4 & 4 & 11 & 3,67 & CB \\
\hline 14 & Meisya Dwi Lestari & 4 & 4 & 4 & 12 & 4 & B \\
\hline 15 & M. Adli & 3 & 4 & 4 & 11 & 3,67 & CB \\
\hline 16 & Musa Riski Haposan & 3 & 4 & 4 & 11 & 3,67 & CB \\
\hline 17 & R. Aisyah Azzahra & 3 & 4 & 4 & 11 & 3,67 & CB \\
\hline 18 & Riska Aura & 4 & 4 & 4 & 12 & 4 & B \\
\hline 19 & Riski Armando & 4 & 4 & 4 & 12 & 4 & CB \\
\hline 20 & Laili Homisanti & 3 & 4 & 4 & 11 & 3,67 & CB \\
\hline 21 & Nurhasanah & 3 & 4 & 4 & 11 & 3,67 & B \\
\hline 22 & Clara Claudia Ardhika & 4 & 4 & 4 & 12 & 4 & B \\
\hline 23 & Eka Syarifuddin & 3 & 4 & 4 & 11 & 3,67 & CB \\
\hline 24 & Fikriansyah & 4 & 4 & 4 & 12 & 4 & B \\
\hline Jumlah Nilai & 82 & 96 & 95 & 273 & 91,04 & \\
\hline Rata-Rata & 3,4 & 4 & 3,9 & 11,37 & 3,79 & CB \\
\hline
\end{tabular}

Tabel 6.

Rentang Nilai Hasil Observasi Siklus I Siswa Kelas IV SD Negeri 196/IV Alam Barajo Tahun 2018

\begin{tabular}{|l|l|l|l|}
\hline Nilai Angka & Predikat & Jumlah Siswa & Persentase \% \\
\hline 5 & Sangat Baik & - & - \\
\hline 4 & Baik & - & - \\
\hline 3 & Cukup Baik & 10 siswa & $41,66 \%$ \\
\hline 2 & Kurang & 14 siswa & $58,34 \%$ \\
\hline 1 & Sangat Kurang & - & - \\
\hline JUMLAH & & 24 siswa & $100 \%$ \\
\hline
\end{tabular}


Tabel 7.

Nilai Hasil Belajar Siswa Pada Siklus II dalam Meringkas dengan Menggunkan Latihan Bervariasi Siswa Kelas IV SD Negeri 196/IV Alam Barajo Tahun 2018

\begin{tabular}{|c|c|c|c|c|c|c|c|c|}
\hline \multirow[b]{2}{*}{ No } & \multirow[b]{2}{*}{ Nama Siswa } & \multicolumn{4}{|c|}{ Aspek yang diobservasi } & \multirow[b]{2}{*}{$\mathrm{Jlh}$} & \multirow[b]{2}{*}{$\begin{array}{l}\text { Rata } \\
\text { Rata }\end{array}$} & \multirow{2}{*}{$\begin{array}{c}\text { Tingka } \\
\mathrm{t} \\
\text { keberh } \\
\text { asilan }\end{array}$} \\
\hline & & 1 & 2 & 3 & 4 & & & \\
\hline 1 & Alif Rafizd & 70 & 60 & 50 & 60 & 240 & 60 & CT \\
\hline 2 & Angelina Maharani & 70 & 55 & 50 & 50 & 225 & 56 & KT \\
\hline 3 & Arif Tarmisih & 70 & 65 & 50 & 65 & 250 & 63 & CT \\
\hline 4 & Amelia & 80 & 60 & 60 & 70 & 270 & 68 & $\mathrm{CT}$ \\
\hline 5 & Bima Arta Kusuma & 70 & 70 & 60 & 60 & 260 & 65 & CT \\
\hline 6 & Fadli & 60 & 60 & 50 & 55 & 225 & 56 & KT \\
\hline 7 & Indah Permata Sari & 70 & 75 & 65 & 60 & 270 & 68 & CT \\
\hline 8 & Jazirah El Fitriyanti & 80 & 50 & 60 & 50 & 240 & 60 & $\mathrm{CT}$ \\
\hline 9 & Julian Pasha & 70 & 55 & 55 & 65 & 245 & 61 & CT \\
\hline 10 & Luvia Pranesti & 70 & 60 & 60 & 50 & 240 & 60 & CT \\
\hline 11 & Lily Angelica & 70 & 70 & 50 & 60 & 250 & 63 & CT \\
\hline 12 & M. Alfio & 75 & 50 & 60 & 60 & 250 & 63 & CT \\
\hline 13 & M. Rafi & 80 & 70 & 50 & 60 & 260 & 65 & CT \\
\hline 14 & Meisya Dwi Lestari & 75 & 60 & 65 & 60 & 260 & 65 & CT \\
\hline 15 & M. Adli & 70 & 70 & 50 & 50 & 240 & 60 & $\mathrm{CT}$ \\
\hline 16 & Musa Riski Haposan & 75 & 60 & 60 & 60 & 255 & 64 & CT \\
\hline 17 & R. Aisyah Azzahra & 80 & 70 & 50 & 50 & 250 & 63 & CT \\
\hline 18 & Riska Aura & 75 & 65 & 60 & 60 & 260 & 65 & CT \\
\hline 19 & Riski Armando & 70 & 55 & 60 & 60 & 245 & 61 & CT \\
\hline 20 & Laili Homisanti & 70 & 65 & 50 & 65 & 250 & 63 & $\mathrm{CT}$ \\
\hline 21 & Nurhasanah & 60 & 60 & 60 & 65 & 245 & 61 & CT \\
\hline 22 & Clara Claudia Ardhika & 75 & 55 & 50 & 60 & 240 & 60 & $\mathrm{CT}$ \\
\hline 23 & Eka Syarifuddin & 60 & 60 & 60 & 50 & 230 & 58 & KT \\
\hline 24 & Fikriansyah & 70 & 70 & 70 & 60 & 270 & 68 & CT \\
\hline \multicolumn{2}{|c|}{ Jumlah Nilai } & 1715 & 1490 & 1360 & 1450 & 5970 & 1496 & \\
\hline \multicolumn{2}{|c|}{ Rata-Rata } & $\begin{array}{l}71,4 \\
6 \\
\end{array}$ & $\begin{array}{l}62,0 \\
8 \\
\end{array}$ & $\begin{array}{l}56,6 \\
7\end{array}$ & $\begin{array}{l}58,5 \\
4\end{array}$ & 248,75 & $\begin{array}{l}62,1 \\
9\end{array}$ & $\mathrm{CT}$ \\
\hline
\end{tabular}

Tabel 8.

Rentang Nilai Hasil Belajar Siklus II PTK Penerapan Latihan Bervariasi dalam Kegiatan Meringkas pada Pembelajaran Bahasa Indonesia Siswa Kelas IV SD Negeri 196/IV Alam Barajo Tahun 2018

\begin{tabular}{|l|l|l|l|}
\hline Nilai Angka & Predikat & Jumlah Siswa & Persentase \% \\
\hline $85-10$ & Sangat Tuntas & - & - \\
\hline $75-84$ & Tuntas & - & - \\
\hline $60-74$ & Cukup Tuntas & 21 siswa & $87,5 \%$ \\
\hline $40-59$ & Kurang Tuntas & 3 siswa & $12,5 \%$ \\
\hline $0-39$ & Sangat Kurang Tuntas & - & - \\
\hline JUMLAH & & 24 siswa & $100 \%$ \\
\hline
\end{tabular}

Hasil observasi pada siklus I nilai rata-rata 3,79\% atau predikat cukup baik sedangkan nilai rata-rata hasil evaluasi siklus II adalah $62,19 \%$ atau predikat cukup tuntas dari jumlah indikator yang diperoleh siswa.Dari hasil dikemukakan bahwa hasil penelitian pada siklus II diperoleh kesimpulan sebagai berikut proses pembelajaran dengan menggunakan latihan bervariasi belum sepenuhnya dapat meningkatkan kemampuan meringkas siswa indicator yang dapat disimak seperti berikut; a. Proses pembelajaran diukur melalui lembar observasi baru mencapai $41,66 \%$ atau siswa 10 siswa yang mendapat predikat baik. b. 
Dampak lanjutannya adalah nilai rata-rata hasil belajar siswa baru mencapai $62,19 \%$ yang berarti bahwa tingkat penguasaan siswa baru mencapai $62,19 \%$ dari jumlah indikator kemampuan meringkas dengan kata lain apabila dihubungkan dengan kriteria keberhasilan belum memenuhi kriteria yang ditetapkan yaitu 75 .

Pada identifikasi masalah pada tindakan siklus II ditemukan masalah-masalah sebagai berikut (1) siswa belum terbiasa diarahkan meringkas dengan sebenarnya(2) kurangnya kecepatan mata siswa dalam mengamati kalimat (3) siswa sulit memahami isi pokok suatu bacaan faktor yang dapat menjadi timbulnya masalah tersebut adalah sebagai berikut (1) proses pembelajaran belum begitu terarah (2) siswa belum bisa meringkas dengan sempurna (3) proses pembelajaran belum terlaksana dengan baik. Hasil refleksi berupa rumusan siklus II yang akan diimplementasikan pada siklus III adalah sebagai berikut: 1 . Siswa perlu diberi tugas stimulus agar mereka tertarik mengikuti sajian pembelajaran disamping itu perlu diingatkan kembali agar siswa mempersiapkan diri lebih baik sebelum mengikuti proses pembelajaran. 2. Tujuan dan manfaat pembelajaran perlu disajikan secara lugas. 3. Memberikan teks bacaan yang lebih menarik. 4. Pada pelaksanaan siklus III perlu diulang kembali tentang teknik meringkas.

\section{Siklus III}

Tabel 9.

\section{Hasil Observasi Proses Belajar Tindakan Siklus III Penerapan Latihan Bervariasi pada Menulis Ringkasan Pembelajaran Bahasa Indonesia Siswa kelas IV SD Negeri 196/IV Alam Barajo Tahun 2018}

\begin{tabular}{|c|c|c|c|c|c|c|c|}
\hline \multirow[t]{2}{*}{ No } & \multirow[t]{2}{*}{ Nama Siswa } & \multicolumn{3}{|c|}{$\begin{array}{l}\text { Aspek yang } \\
\text { diobservasi }\end{array}$} & \multirow[t]{2}{*}{ Jlh } & \multirow{2}{*}{$\begin{array}{l}\text { Rata } \\
\text { Rata }\end{array}$} & \multirow[t]{2}{*}{ Predikat } \\
\hline & & 1 & 2 & 3 & & & \\
\hline 1 & Alif Rafizd & 5 & 4 & 4 & 14 & 4,67 & B \\
\hline 2 & Angelina Maharani & 5 & 5 & 5 & 15 & 5 & SB \\
\hline 3 & Arif Tarmisih & 4 & 5 & 4 & 13 & 4,33 & B \\
\hline 4 & Amelia & 4 & 5 & 4 & 13 & 4,33 & B \\
\hline 5 & Bima Arta Kusuma & 4 & 4 & 4 & 12 & 4 & B \\
\hline 6 & Fadli & 4 & 4 & 4 & 12 & 4 & B \\
\hline
\end{tabular}

\begin{tabular}{|c|l|c|c|c|c|c|c|}
\hline 7 & Indah Permata Sari & 4 & 4 & 4 & 12 & 4 & B \\
\hline 8 & Jazirah El Fitriyanti & 5 & 5 & 5 & 15 & 5 & SB \\
\hline 9 & Julian Pasha & 5 & 4 & 4 & 13 & 4,33 & B \\
\hline 10 & Luvia Pranesti & 4 & 4 & 4 & 12 & 4 & B \\
\hline 11 & Lily Angelica & 4 & 4 & 4 & 12 & 4 & B \\
\hline 12 & M. Alfio & 4 & 5 & 5 & 14 & 4,67 & B \\
\hline 13 & M. Rafi & 4 & 5 & 5 & 12 & 4 & B \\
\hline 14 & Meisya Dwi Lestari & 4 & 4 & 4 & 12 & 4 & B \\
\hline 15 & M. Adli & 4 & 4 & 5 & 13 & 4,33 & B \\
\hline 16 & Musa Riski Haposan & 4 & 5 & 4 & 13 & 4,33 & B \\
\hline 17 & R. Aisyah Azzahra & 4 & 4 & 4 & 12 & 4 & B \\
\hline 18 & Riska Aura & 5 & 4 & 5 & 14 & 4,67 & B \\
\hline 19 & Riski Armando & 4 & 4 & 5 & 13 & 4,33 & B \\
\hline 20 & Laili Homisanti & 4 & 5 & 5 & 14 & 4,67 & B \\
\hline 21 & Nurhasanah & 4 & 5 & 5 & 13 & 4,33 & B \\
\hline 22 & Clara Claudia Ardhika & 5 & 5 & 5 & 15 & 5 & SB \\
\hline 23 & Eka Syarifuddin & 4 & 4 & 4 & 12 & 4 & B \\
\hline 24 & Fikriansyah & 5 & 4 & 5 & 14 & 4,67 & B \\
\hline Jumlah Nilai & 103 & 104 & 107 & 314 & 104,66 & \\
\hline Rata-Rata & 4,29 & 4,33 & 4,46 & 13,08 & 4,36 & \\
\hline
\end{tabular}


Tabel 10.

Rentang Nilai Hasil Observasi Siklus III Siswa Kelas IV SD Negeri 196/IV Alam Barajo Tahun 2018

\begin{tabular}{|l|l|l|l|}
\hline Nilai Angka & Predikat & Jumlah Siswa & Persentase $\%$ \\
\hline 5 & Sangat Baik & 4 siswa & $16,66 \%$ \\
\hline 4 & Baik & 20 siswa & $83,34 \%$ \\
\hline 3 & Cukup Baik & - & - \\
\hline 2 & Kurang & - & - \\
\hline 1 & Sangat Kurang & - & - \\
\hline JUMLAH & & 24 siswa & $100 \%$ \\
\hline
\end{tabular}

Tabel 11.

Hasil Belajar Siswa pada Siklus III dalam Meringkas dengan Menggunkan Latihan Bervariasi Siswa Kelas IV SD Negeri 196/IV Alam Barajo Tahun 2018

\begin{tabular}{|c|c|c|c|c|c|c|c|c|}
\hline \multirow[t]{2}{*}{ No } & \multirow[t]{2}{*}{ Nama Siswa } & \multicolumn{4}{|c|}{$\begin{array}{l}\text { Aspek yang } \\
\text { diobservasi }\end{array}$} & \multirow[t]{2}{*}{ Jlh } & \multirow[t]{2}{*}{$\begin{array}{l}\text { Rata } \\
\text { Rata } \\
\end{array}$} & \multirow{2}{*}{$\begin{array}{c}\text { Tingkat } \\
\text { keberhasila }\end{array}$} \\
\hline & & 1 & 2 & 3 & 4 & & & \\
\hline 1 & Alif Rafizd & 75 & 70 & 70 & 80 & 295 & 73,75 & CT \\
\hline 2 & Angelina Maharani & 75 & 75 & 80 & 80 & 310 & 77,5 & $\mathrm{~T}$ \\
\hline 3 & Arif Tarmisih & 75 & 75 & 80 & 80 & 310 & 77,25 & $\mathrm{~T}$ \\
\hline 4 & Amelia & 85 & 80 & 85 & 80 & 330 & 82,5 & $\mathrm{~T}$ \\
\hline 5 & Bima Arta Kusuma & 75 & 80 & 85 & 80 & 320 & 80 & $\mathrm{~T}$ \\
\hline 6 & Fadli & 70 & 70 & 70 & 75 & 285 & 71,25 & CT \\
\hline 7 & Indah Permata Sari & 80 & 85 & 80 & 80 & 325 & 81,25 & $\mathrm{~T}$ \\
\hline 8 & Jazirah El Fitriyanti & 85 & 75 & 70 & 80 & 310 & 77,5 & $\mathrm{~T}$ \\
\hline 9 & Julian Pasha & 80 & 70 & 80 & 80 & 310 & 77,5 & $\mathrm{~T}$ \\
\hline 10 & Luvia Pranesti & 75 & 80 & 80 & 80 & 305 & 76,25 & $\mathrm{~T}$ \\
\hline 11 & Lily Angelica & 75 & 80 & 70 & 80 & 305 & 76,25 & $\mathrm{~T}$ \\
\hline 12 & M. Alfio & 80 & 85 & 75 & 80 & 320 & 80 & $\mathrm{~T}$ \\
\hline 13 & M. Rafi & 85 & 80 & 70 & 80 & 315 & 78,75 & $\mathrm{~T}$ \\
\hline 14 & Meisya Dwi Lestari & 80 & 80 & 75 & 80 & 320 & 80 & $\mathrm{~T}$ \\
\hline 15 & M. Adli & 75 & 80 & 75 & 80 & 310 & 77,5 & $\mathrm{~T}$ \\
\hline 16 & Musa Riski Haposan & 85 & 80 & 70 & 75 & 310 & 77,5 & $\mathrm{~T}$ \\
\hline 17 & R. Aisyah Azzahra & 85 & 80 & 70 & 75 & 310 & 77,5 & $\mathrm{~T}$ \\
\hline 18 & Riska Aura & 80 & 75 & 80 & 80 & 305 & 76,25 & $\mathrm{~T}$ \\
\hline 19 & Riski Armando & 75 & 75 & 75 & 80 & 305 & 76,25 & $\mathrm{~T}$ \\
\hline 20 & Laili Homisanti & 75 & 80 & 70 & 80 & 305 & 76,25 & $\mathrm{~T}$ \\
\hline 21 & Nurhasanah & 70 & 75 & 75 & 80 & 300 & 75 & $\mathrm{~T}$ \\
\hline 22 & Clara Claudia Ardhika & 80 & 75 & 70 & 75 & 300 & 75 & $\mathrm{~T}$ \\
\hline 23 & Eka Syarifuddin & 70 & 75 & 75 & 75 & 295 & 73,75 & $\mathrm{CT}$ \\
\hline 24 & Fikriansyah & 75 & 80 & 80 & 80 & 315 & 78,75 & $\mathrm{~T}$ \\
\hline \multicolumn{2}{|c|}{ Jumlah Nilai } & $\begin{array}{l}186 \\
5 \\
\end{array}$ & $\begin{array}{l}186 \\
5\end{array}$ & $\begin{array}{l}18 \\
00\end{array}$ & $\begin{array}{l}18 \\
85\end{array}$ & 7415 & $\begin{array}{l}1853,7 \\
5\end{array}$ & \\
\hline \multicolumn{2}{|c|}{ Rata-Rata } & $\begin{array}{l}77, \\
71\end{array}$ & $\begin{array}{l}77, \\
71\end{array}$ & 75 & $\begin{array}{l}78, \\
54\end{array}$ & $\begin{array}{l}308,9 \\
5 \\
\end{array}$ & 77,24 & $\mathrm{~T}$ \\
\hline
\end{tabular}

Keterangan :

1. Mampu membaca dengan baik bacaan yang akan dirangkum

2. Mampu memahami isi secara utuh terhadap bacaan yang akan dirangkum

3. Mampu menemukan ide-ide pokok ataupun kalimat topik dalam bacaan yang akan dirangkum

4. Mampu menyusun kembali ide-ide maupun kalimat topik yang telah ditemukan menjadi sebuah tulisan utuh. 
Tabel 12.

Rentang Nilai Hasil Belajar Siklus III PTK Penerapan Latihan Bervariasi dalam Kegiatan Meringkas pada Pembelajaran Bahasa Indonesia Siswa Kelas IV SD Negeri 196/IV Alam Barajo Tahun 2018

\begin{tabular}{|l|l|l|l|}
\hline Nilai Angka & Predikat & Jumlah Siswa & Persentase \% \\
\hline $85-10$ & Sangat Tuntas & - & - \\
\hline \hline $75-84$ & Tuntas & - & - \\
\hline $60-74$ & Cukup Tuntas & 21 siswa & $87,5 \%$ \\
\hline $40-59$ & Kurang Tuntas & 3 siswa & $12,5 \%$ \\
\hline $0-39$ & $\begin{array}{l}\text { Sangat Kurang } \\
\text { Tuntas }\end{array}$ & - & - \\
\hline JUMLAH & & 24 siswa & $100 \%$ \\
\hline
\end{tabular}

Hasil analisis dari tabel 4.12 diatas diketahui bahwa pada siklus III peningkatan kemampuan meringkas sudah mencapai kualifikasi berhasil.hal ini dapat dilihat dari hasil observasi dan evaluasi pada siklus III. Hasil observasi pada siklus III nilai rata-rata 4,36\% atau predikat baik sedangkan nilai rata-rata hasil evaluasi siklus III adalah 77,24\% atau predikat tuntas dari jumlah indikator yang diperoleh siswa.Dari sini terlihat kemampuan meringkas pada pelajaran bahasa Indonesia dengan menerapkan latihan bervariasi pada siklus III mencapai 77,24\%. Siswa yang mencapai predikat baik 20 siswa $/ 83,34 \%$ dan mendapat nilai sangat baik 4 siswa /16,66\%(hasil observasi siklus III) sedangkan hasil evaluasi siklus III siswa yang mendapat predikat cukup 3 siswa /12,5\% dibanding pada hasil belajar siklus II yang hanya mencapai ratarata $62,19 \%$ berarti terjadi kenaikan pada hasil belajara siswa pada pembelajaran meringkas tindakan siklus III.

Dari hasil penelitian tersebut dapat disimpulkan bahwa penggunaan latihan bervariasi dalam meningkatkan kemampuan siswa dalam meringkas pada pembelajaran bahasa Indonesia menjadi meningkat, setelah siklus III dapat dinyatakan berhasil . Keberhasilan ini ditunjukkan oleh indikator sebagai berikut;

a. Hasil observasi pada siklus III mencapai 20 siswa berpredikat baik $(83,34 \%)$ dan 4 siswa berpredikat baik sekali $(16,66 \%)$.

b. Hasil belajar siswa pada siklus ke III mencapai nilai rata-rata 77,24\%

Pada tindakan siklus III terlihat kemampuan meringkas menjadi meningkat hal ini berarti latihan bervariasi dapat meningkatkan kemampuan siswa yang mana penerapan latihan bervariasi dapat meningkatkan kemampuan meringkas pada pelajaran bahasa Indonesia.

\section{Pembahasan}

Hasil penelitian tindakan kelas dengan menggunakan pola tiga siklus ternyata dapat menguji hipotesis tindakan yang diajukan dalam penelitian ini. Berdasarkan bervariasi untuk menungkatkan kemampuan siswa dalam mata pelajaran bahasa Indonesia sehingga proses pembelajaran menjadi aktif dan komunikatif antara guru dan siswa, siswa dengan siswa.

Untuk melihat lebih jelas keterhubungan hasil penelitian pada masingmasing siklus dengan criteria keberhasilan yang ditetapkan, disajikan rekaman data perkembangan hasil observasi dan evaluasi pada setiap siklus sebagai berikut: 
Tabel 13.

Data Hasil Penelitian Tindakan Kelas (PTK) Penerapan Latihan Bervariasi dalam Kegiatan Meringkas pada Pembelajaran Bahasa Indonesia Siswa Kelas IV SD Negeri 196/IV Alam Barajo Tahun 2018

\begin{tabular}{|c|l|l|l|l|l|}
\hline \multirow{2}{*}{ No } & \multirow{2}{*}{$\begin{array}{c}\text { Nama } \\
\text { Sekolah }\end{array}$} & \multicolumn{1}{|c|}{$\begin{array}{c}\text { Penilaian Hasil } \\
\text { Belajar }\end{array}$} & \multicolumn{3}{|c|}{ Hasil PTK } \\
\cline { 3 - 6 } & SD & Observasi & $3,00 /$ cukup & $\begin{array}{l}\text { S,79/cukup } \\
\text { baik }\end{array}$ & $4,36 /$ Baik \\
& $\begin{array}{l}\text { Negeri } \\
1\end{array}$ & $\begin{array}{l}\text { keefektifan } \\
\text { siswa }\end{array}$ & baik & & \\
\cline { 3 - 6 } & $\begin{array}{l}\text { Alam } \\
\text { Barajo }\end{array}$ & Kemampuan & 52 & 62,19 & 77,24 \\
& $\begin{array}{l}\text { Mota } \\
\text { Kambi }\end{array}$ & & & & \\
\hline
\end{tabular}

Walaupun latihan bervariasi telah terbukti dapat meningkatkan kemampuan siswa dalam meringkas namun latihan bervariasi tersebut bukan berarti segala-galanya dapat mengatasi semua masalah. Apa yang diperoleh melalui tindakan ini hanyalah salah satu dimana kesahihan dalam penerapan latihan bervariasi ini masih perlu diuji pada Dari tabel diatas yang diukur hasil belajar siswa keseluruhan menunjukkan adanya peningkatan pada setaiap siklus . Hasil observasi keefektifan siswa pada siklus I adalah 3,00 dengan predikat cukup baik ,siklus II 3,79 dengan predikat cukup baik sedangkan pada siklus III 4,36 dengan predikat baik. Hasil evaluasi kemampuan meringkas siswa pada siklus I adalah 52(52\%) siklus II $62,19(52,19 \%)$ dan siklus III 77,24(77,24\%) seluruh target kriteria dapat terpenuhi oleh karena itu hipotesis yang diajukan dapat diterima.

Pengajaran bahasa Indonesia di sekolah dasar berdasarkan kurikulum KTSP 2006 secara umum dikembangkan menjadi ketrampilan berbahasa yang meliputi mendengar, berbicara, membaca, menulis, PPNo19 tahun 2005 pasal 26 ayat 3 disebtukan bahwa "kompetensi kelulusan mata pelajaran bahasa Indonesia menekankan pada kemampuan membaca dan menulis sesuai dengan jenjang pendidikan" hal ini ditunjang juga pernyataan pada pasal 21 ayat 2 yang "menyatakan perencanaan proses pembelajaran mengembangkan budaya membaca dan menulis". Untuk mengatasi masalah ini diterapkan latihan bervariasi agar kemampuan sisiswa dalam meringkas akan menjadi meningkat siswa dapat melakukan meringkas dengan baik dengan susunan kalimat yang utuh dengan demikian siswa akan lebih mudah memahami isi dari pokok suatu bacaan yang mereka baca

Dengan menggunakan latihan bervariasi siswa akan lebih cepat menulis sesuai dengan isi pokok suatu kalimat yang baik dan siswa dapat memahami isi pokok suatu bacaaan. Menurut Tarigan(1996) mengungkapkan bahwa membaca yaitu proses pemerolehan pesan yang disampaikan oleh seorang penulis melalui tulisan.

Berdasarkan pengertian yang diuraikan diatas dapat diartikan bahwa membac adalah proses pengucapan tulisan untuk mendapatkan isi yang terkandung didalamnya.

Latihan bervariasi adalah cara untuk mencapai prestasi yang lebih baik agar dalam proses pembelajran tidak membosankan. Latihan ini perlu diperbanyak tetapi berbeda dengan latihan sebelumnya. Kegiatan ini dapat membantu siswa dalam mengembangkan kemampuan meringkas.

\section{SIMPULAN}

Berdasarkan hasil penelitian tindakan jelas yaitu dengan menerapkan latihan bervariasi dalam materi meringkas pada Mata Pelajaran Bahasa IndonesiaSiswa Kelas IV SD Negeri 196/ IV Alam Barajo Kota Jambi terdapat peningkatan kemampuan meringkas.Hasil belajar siswa dengan rata-rata 52 pada siklus I,62,19pada siklus II terbukti terjadi peningkatan kemampuan meringkas dan keefektifan siswa setelah menerapkan latihan bervariasi pada siklus III hasil belajar mencapai rata-rata77,24. Dengan demikian penerapan latihan bervariasi dalam pembelajaran bahasa Indonesia pada materi meringkas dapat 
meningkatkan kemampuan meringkas siswa melebihi kriteria ketuntasan secara klasikal yaitu rata-rata 75. Hasil yang diperoleh siswa pada siklus III telah mencapai 77,24 diatas Kriteria ketuntasan secara klasikal yang telah ditetapkan.

\section{DAFTAR PUSTAKA}

Anonim, 1996, Penyelenggaraan pendidikan di SD. Jakarta;Depdikbud , 1997. Kamus Besar bahasa Indonesia. Surabaya , 2008. Peraturan Mentri Pendidikan Nasional. Jakarta;Depdiknas , 2011. Buku Panduan Penulisan Proposal dan Skripsi Hasil PTK Jambi;Kemendiknas Unja FKIP Depdiknas, 2003. Kurikulum Berbasis Kompetensi. Jakarta;Depdiknas http://Luthfisurrah.wordpress.com/2016/08/24/meringkas-menyadur-dan-menstranskip.Dakses 05 januari 2018

Suparno,2009. Bahasa dan Sastra Indonesia.Jakarta;Bumi Aksara

Maryono,2007. Bahasa Indonesia Untuk Penulis Ilmiah,UNJA;FKIP

Subroto,1994. Proses Belajar Mengajar.Jakarta;Reneka Cipta

Tarigan,1996. Pendidikan Bahasa Indonesia 3.Jakarta;Universitas terbuka 